\title{
A presença feminina no imaginário dos artistas brasileiros
}

\section{A imagem da mulher: um estudo de arte brasileira.}

COSTA, Cristina.

Rio de Janeiro: Ed. Senac, 2002. $199 \mathrm{p}$.

Cristina Costa é doutora em Ciências Sociais e livre-docente em Ciências da Comunicação pela Escola de Comunicações e Artes da Universidade de São Paulo, USP.

O livro A imagem da mulher: um estudo de arte brasileira é resultado de uma longa pesquisa, iniciada na década de 1980 , concebida e efetuada no intuito de descortinar na arte brasileira a ênfase dada à mulher e à posição desta na sociedade. Analisando e interpretando reproduções de obras de diferentes artistas (cerca de 1.300 obras de arte do acervo dos museus de São Paulo, Rio de Janeiro, Bahia e Minas Gerais foram pesquisadas), Cristina Costa fez um estudo detalhado, mostrando como a arte pode ajudar a compreender a sociedade e vice-versa.

Por meio de registro fotográfico e de catalogação e seleção de imagens femininas, a autora analisou os papéis desempenhados por mulheres na formação e na organização produtiva da sociedade brasileira, passeando pelos séculos XVII, XVIII, XIX e pelo início do XX, e dirigindo a atenção a cinco movimentos artísticos: o barroco, o neoclassicismo, o romantismo, o realismo e o modernismo. A pesquisadora fez mais do que descrever a concepção plástica e os estilos das obras estudadas. Aspecto central de seu estudo foi a tentativa de desvendar, em um procedimento que evoca o "paradigma indiciário de Carlo Ginzburg", ' os diferentes contextos 
sociais, políticos e econômicos em que ocorreu a produção da pintura artística no Brasil.

Pode-se afirmar que, pela interpretação das imagens, Cristina Costa faz um interessante contraponto às análises generalizadoras que ignoram as diferenças e particularidades dos agentes sociais. Fica evidente ao leitor que esse livro é, na verdade, fruto do envolvimento da autora, a um só tempo, com as ciências sociais e com a arte, uma interação que a permitiu observar, por exemplo, na década de 1960, "[o] silêncio da ciência em torno [das particularidades e diferenças de sexo e de gênero] nas formações sociais" (p. 20), e, na década de 1970, a mulher como tema central de diferentes linguagens artísticas.

Estimulada por essas percepções, e crítica das abordagens predominantes acerca da produção sobre a problemática feminina nas ciências sociais, percebeu ser necessário rever idéias e conceitos, para o que foi buscar nas obras de arte a fonte para a sua narrativa sobre o papel social da mulher na sociedade brasileira. Escutemos a autora: "A minha formação em artes plásticas e a familiaridade que com ela desenvolvera em relação à produção artística apresentavam um contraponto ideal a esse 'silêncio' a respeito da mulher na produção sociológica, pois, enquanto os textos e as pesquisas passavam ao largo das diferenças de gênero, através de análises generalizantes que tinham como base a condição masculina, as artes desenvolviam um discurso que ressaltava diferenças e discrepâncias e que se detinha de forma acentuada na figura feminina, fazendo dela um dos seus mais constantes temas" (p. 20).

Portanto, o livro apresenta-se edificado sobre dois pilares. "O primeiro refere-se à constatação de que o discurso sociológico, apesar de sua objetividade e cientificismo, tendia a descrever situações sociais, ignorando as diferenças e particularidades dos agentes sociais [...]. O segundo pilar refere-se à hipótese de que a arte poderia corrigir essa visão generalista, revelando particularismos a respeito de temas sobre os quais se debruça a ciência e sobre os quais haviam se calado os cientistas sociais" ( $p$. 23).

O texto é constituído de 23 capítulos distribuídos em cinco partes temáticas. $\mathrm{Na}$ primeira, referente à discussão sobre Sociologia e Arte, Cristina Costa trabalha conceitos e modelos de análise em Sociologia da Arte. Para isso, busca na hermenêutica a base para a interpretação das manifestações simbólicas e para a análise das relações destas com as circunstâncias históricas, sociais e políticas nas quais foram concebidas.

A segunda, a terceira e a quarta partes do livro tratam, respectivamente, do barroco brasileiro, do século XIX - que enfatiza o estilo neoclássico e o romantismo - e dos modernismos do início do século XX. Cabe ressaltar, sobre essas partes, que a autora percebeu uma grande falta de sintonia entre as imagens analisadas e os documentos históricos e estudos sociológicos do período entre o século XVII e a primeira metade do século XX. São exemplos os retratos de mulheres do século XIX. No estudo iconográfico das obras desse período, Cristina Costa observou que os retratos femininos foram realizados em um estilo sóbrio e severo e que o padrão estético era idêntico ao dos retratos masculinos. Como "o retrato é um tipo de pintura que envolve não somente a técnica mas também as expectativas do retratado e de seu grupo de referência, [a autora concluiu] que a vida da mulher e sua inserção na sociedade da época aproximavamse mais da condição masculina do que os estudos históricos pressupunham" (p. 102).

A pesquisadora logrou vislumbrar aquele perfil da mulher com o auxílio de informações obtidas em estudos científicos e obras de ficção. De fato, autores como "Machado de Assis; Cornélio Pires Jorge de Andrade, escritor e folclorista; Jorge Caldeira, escritor e dramaturgo; Gilda de Mello e Souza, socióloga; Laura de Mello e Souza, historiadora; e Alcântara Machado, escritor e historiador, entre outros, relatam a vida das mulheres da elite cafeeira"(p. 103). No final da investigação, Cristina Costa chegou a conclusão de que a mulher desempenhou um papel importantíssimo no Brasil agrário. Ela era chefe do grupo familiar e também partilhava com o homem o poder de liderança em diferentes aspectos da vida cotidiana. "A falsa idéia de que as mulheres não tinham importância social e que, submissas a seus maridos, eram peças insignificantes no tabuleiro da História é devido ao fato de sua vida resumir-se ao universo doméstico e familiar" (p. 105).

Outro momento interessante desse segmento do livro, que cabe ser ressaltado, refere-se ao modernismo, correspondente ao início do século XX. Associado pela autora a um importante estágio na trajetória social, esse período apresenta mudanças e rupturas culturais e estéticas. Para ela, de fato, "[s]ão os Modernismos que pretendem, cada um à sua maneira, dar conta de um mundo em transformação" (p. 135). Nesse mundo, as mulheres deixam de ser simplesmente modelos 
e passam a se auto-retratar, além de serem mais atuantes na esfera pública, revelando uma participação mais efetiva na sociedade.

Na quinta e última parte do livro a autora aborda, de forma concisa, algumas questões referentes à arte clássica ou erudita e cultura de massa, assim como aos gêneros artísticos e tipos femininos. A intenção da autora é, certamente, mostrar que, entre todas as representações de mulheres analisadas, existe um fio condutor que perpassa todos os períodos pesquisados: a busca do entendimento de como é a mulher brasileira.

$O$ que singulariza a pesquisa de Cristina Costa, considerando os diferentes aspectos que integram a sua análise, é o uso de imagens como fonte histórica. Segundo a pesquisadora, a interpretação de imagens em documentos iconográficos passou a ser, na década de 1980, um elemento importante para a História, a Antropologia e a Sociologia. "O historiador Michel Vovelle, um dos criadores da história das mentalidades, assegura que $o$ uso de fontes iconográficas é de fundamental importância para o trabalho de pesquisa, por serem elas muito mais do que um comentário ilustrado dos textos escritos; elas falam mais que estes, com o seu discurso autônomo e próprio, diz ele, 'falam onde o texto se cala'" (p. 23).

Sobre esse assunto, o historiador Eduardo França Paiva escreve: "A iconografia é, certamente, uma fonte histórica das mais ricas, que traz embutida as escolhas do produtor e todo o contexto no qual foi concebida, idealizada, forjada ou inventada. Nesse aspecto, ela é uma fonte como qualquer outra $e$, assim como as demais, tem que ser explorada com muito cuidado". ${ }^{2}$

Paiva ainda assinala que "[a] imagem não é um retrato de uma verdade, nem a representação fiel de eventos ou de objetos históricos, assim como teriam acontecido ou assim como teriam sido. Isso é irreal e pretensioso. A História e os diversos registros históricos são sempre resultados de escolhas, seleções e olhares de seus produtores e dos demais agentes que influenciaram essa produção. [...] [l]sso significa que as fontes nunca são completas, nem as versões historiográficas são definitivas. [...] Fontes e versões carregam em si temporalidades distintas, porque são construídas e reconstruídas a cada época". ${ }^{3}$

É certo que a imagem como objeto de pesquisa ainda apresenta problemas, haja vista que ainda não logrou obter na História, nas Ciências Sociais e em outras disciplinas os instrumentais teóricos suficientes ao seu tratamento. Por conta disso, assim como se observa no estudo intitulado Imagens negociadas, de Sérgio Miceli, ${ }^{4}$ a abordagem de Cristina Costa tem, pode-se dizer, um caráter inovador. Com efeito, nela a imagem não é considerada apenas como uma coadjuvante, uma mera ilustração, uma referência histórica ou uma curiosidade. Ao contrário, para a autora, é a partir das imagens que se elabora, reconstitui e ressignifica o quadro das relações sociais e o papel da mulher nessas relações.

É importante destacar que o referido caráter inovador tem a ver, igualmente, com a escolha da metodologia utilizada na pesquisa, cuja inspiração foi buscada em estudos nas áreas da fenomenologia da percepção e da sociologia do imaginário, além de ter se apoiado em valiosas fontes iconográficas. Escutemos mais uma vez a autora:

"Nessa tendência de pesquisa em sociologia da arte, história das mentalidades e estudos da percepção, o homem é tomado em sua totalidade, como agente social, como ser cognitivo e simbólico, como organismo físico, sensível e significante. $\mathrm{E}$, assim como não existe ruptura entre sua objetividade e sua subjetividade, também não há oposição entre realidade e suas formas de representação. Tratase, portanto, de uma postura totalizante e unificadora que não privilegia os aspectos objetivos em relação aos subjetivos daquilo que entendemos por realidade e, igualmente, não atribui mais validade aos enunciados científicos do que às formulações poéticas" (p. 40).

Para finalizar, cabe também aludir a uma decepção com a obra, relativa à própria natureza da pesquisa. Embora se trate de uma investigação que utiliza como fonte essencial a imagem, a documentação visual apresentada é escassa. De outra parte, a autora não elabora nenhum tipo de diálogo entre as imagens, o que faz com que o objetivo principal de sua obra, a saber, a interpretação de imagens, perca espaço em benefício de longas descrições metodológicas e de estudos de períodos históricos ou estilos artísticos. Na verdade, o material iconográfico apresentado é explorado só superficialmente, deixando no leitor uma sensação de 'quero mais'. No entanto, tendo em vista que os estudos dessa natureza são pouco numerosos e pouco considerados, cabe registrar que o trabalho de Cristina Costa é altamente instigante para um debate sobre 0 uso de imagens de obras de arte como fontes nos estudos de História. 
' GINZBURG, Carlo. Mitos, emblemas, sinais: morfologia e história. São Paulo: Companhia das Letras, 1996.

2 PAIVA, Eduardo França. História \& Imagens. Belo Horizonte: Autêntica, 2002. (Coleção História \& Reflexões, 1). p. 17. ${ }^{3}$ lbid., p. 19-20.

${ }^{4}$ MICELI, Sérgio. Imagens negociadas: retratos da elite brasileira (1920-40). São Paulo: Companhia das Letras, 1996. Nesse livro, Sérgio Miceli reconstitui o quadro de relações interpessoais, que configuravam o mundo cultural entre os anos 1920 e 1940, a partir dos retratos das pessoas da sociedade brasileira pintados por Cândido Portinari. Na mesma linha de Cristina Costa, Miceli constrói o seu argumento a partir da imagem.

Jacqueline Wildi Lins Universidade para o Desenvolvimento do Estado de Santa Catarina 